\title{
PENGEMBANGAN MEDIA PEMBELAJARAN KARIR "ROE" BERBASIS PERMAINAN SEBAGAI UPAYA PENINGKATAN WAWASAN KARIR SISWA
}

\author{
Sudharno Dwi Yuwono ${ }^{1}$ \\ Restu Aidah ${ }^{2}$
}

\begin{abstract}
Abstrak
Layanan klasikal sebagai strategi pencapaian kompetensi dalam bidang karir selama ini tidak menggunakan media yang tepat. media yang menyenangkan adalah media permaian. Bermain membuat siswa tidak bosan dalam belajar. Dilihat dari hal itu maka penting dikembangkan media layanan klasikal dalam bidang karir berbasis permainan. Penelitian ini memiliki tujuan untuk mengembangkan sebuah media mengenai infromasi mengenai berbagai macam profesi yang dapat digunakan dalam layanan klasikal dan untuk mengetahui seberapa efektifkah media ini dapat dugunakan untuk mengembangkan wawasan karir siswa. Perumusan pada penelitian ini dirumuskan masalah apakah dapat dikembangkan media karir untuk meningkatkan wawasan karir siswa? Media yang akan dikembangkan peneliti adalah media permainan papan bergambar, dadu dan kartu. Isi media berupa nama-nama pekerjaan dan kualifikasi yang dibutuhkan. Media ini akan dibuat dengan dasar teori Anne Roe. Media dirancang agar dapat dimainkan oleh minimal dua orang dan maksimal lima orang. Pada penelitian kali ini sesuai dengan metode yang digunakan yaitu Research and Development (R\&D), maka peneliti menggunakan dua instrumen penelitian. Dua instrumen tersebut digunakan untuk alpha tes. Tiap aspek penilaian didasarkan pada teori Winarno (2009), yang kemudian dikembangkan menjadi butirbutir pertanyaan.
\end{abstract}

Kata kunci: Media Permaianan Halma, Wawasan Karir Siswa

\begin{abstract}
The classical services of guidance and counseling in the school as a strategy to achieve the career competency of the student all this time was not using the right learning media like one based on the game that will make the learning process run joyfully for the student. Because of that, then it is important to develop a learning media for the classical services in the field of career of the student through game. This research aims are to develop a learning media about the information of the kind of profession and to discover the effectiveness of this media for improving the career insight of the student. The question of this research is about how the use of Halma media for improving the career insight of the student. The Media developed by the researchers is a Halma game that is consist of a pictorial board, a dice and cards. Overall, the game is including the kind of profession and the qualification required for each profession. This media made based on the theory of Anne Roe. The media designed to be played by at least two people and maximum five people. The methodology of the research is the Research and Development (R\&D) method, the research use two kind of research instruments, those ones use for alpha tesy.
\end{abstract}

\footnotetext{
${ }^{1}$ Dosen Jurusan Bimbingan dan Konseling UHAMKA, sudharnodwi.kuliah@gmail.com

${ }^{2}$ Guru Bimbingan dan Konseling
} 
Each aspect of the assessment is based on the theory of Winarno (2009), henceforth developed into the item of questions.

\section{Keywords : Halma Career Game, the jobs and qualifications required}

\section{PENDAHULUAN}

Di Indonesia perbandingan antara siswa dan guru BK yang ideal yaitu 1:150 (Depdiknas, 2008), walaupun demikian masih banyak Sekolah yang tidak memenuhi kondisi tersebut. Menurut Mungin, kebutuhan guru BK secara nasional sebesar 129.000 (Huda, 2013). Kekurangan tersebut memicu terjadinya perbandingan guru BK dengan siswa di SMKN 57 yang tidak seimbang yang dapat mencapai 1:225 (Erastia, 2013) bahkan di Sekolah Taman Siswa dapat mencapai 1:1400 (Aidah, 2015).

Perbandingan rasio yang tidak ideal dapat menjadi penyebab bagi guru BK dalam menyelenggarakan program BK dengan tidak profesional. Tuntutan penyelenggaraan layanan Bimbingan dan Konseling yang profesional tertera pada permendikbud 111 pasal 1 dan 3 (Kemendikbud, 2014). Salah satu ciri penyelenggaraan program layanan BK yang professional adalah tercapainya tujuan pembelajaran dengan terukur.

Berdasarkan survei mengenai pengetahuan pekerjaan pada siswa SMK 26 dengan responden sebanyak 30 siswa diketahui profesi teratas berturut-turut yaitu Dokter, Apoteker, Guru, TNI, Karyawan, Pilot, Polisi, Perawat, Artis, Satpam (Bella, 2015) dan di SMK Kejuruan Farmasi dengan responden sebanyak 36 siswa diketahui Guru, Sopir, Dosen, Aktor, Arsitek, Direktur, HRD, Manager, dan Acounting (Fitriyani, 2015). Hasil survei tersebut menunjukan pengetahuan mengenai berbagai bidang pekerjaan yang diketahui siswa tidak berhubungan dengan pendidikan (kejuruan) yang mereka sedang jalani.

Merujuk hasil survei yang menunjukan pengetahuan siswa mengenai berbagai bidang pekerjaan yang sangat terbatas dan tidak berhubungan dengan kejuruan yang diambil menjadi indikator penyelenggaraan layanan klasikal dalam bidang karir pada jenjang SMP tidak optimal. Menurut Badrujaman (2011), program BK yang diselenggarakan di Sekolah masih tidak dipedulikan siswa bahkan tidak diminati.

Agar layanan dasar yang berbentuk klasikal dapat menyenangkan maka perlu keterlibatan aktif siswa. Permasalahannya perbandingan jumlah siswa dan guru BK tidak seimbang, sehingga guru BK tidak dapat melayani keaktifan seluruh siswa. Oleh karena itu, guru BK memerlukan media agar layanan lebih efektif, melibatkan siswa secara aktif dan menyenangkan. Menurut Pike 1989 (dalam Sileberman, 2006), pembelajaran dengan media visual dapat meningkatkan ingatan 14 hingga $38 \%$.

Di Indonesia layanan Bimbingan Konseling teridiri dari empat bidang layanan. Layanan dasar, Layanan Peminatan dan Perencanaan Inividual, Layanan Responsif, dan Dukungan Sistem.Beban kerja masingmasing di SMP secara beturut-turut $44-55 \%$, 5-10\%, 20-30\%, dan 10-15\% (ABKI, 2006). Layanan dasar dirasa sangat efektif karena dapat diselenggarakan dengan siswa yang cukup banyak hingga mencapai maksimal 32 siswa.

Harsantik (2014), telah berhasil mengembangkan media game tebak gambar untuk siswa SMP untuk mempermudah penyempaian materi. Media permainan seperti yang dikembangkan oleh Harsantik juga telah dikembangkan oleh Prastiwi. Berdasarkan penelitian Prastiwi (2014), ia berhasil mengembangkan media layanan bimbingan kelompok berbasis permainan ular tangga. Media permainan terus dikembangkan karena dianggap membantu guru BK dalam memberikan layanan.

Tujuan penguasaan kompetensi 
pada siswa SMP kelas IX salah satunya adalah mampu mengidetifikasi arah karir (Badrujaman, 2011). Kemampuan identifikasi tersebut penting karena siswa kelas IX setara dengan 14 tahun atau telah memasuki fase ekspolrasi karir.

Super (dalam Rojewski, 2005) menyatakan bahwa waktu yang paling penting dalam mengembangkan dan memiliki aspirasi pekerjaan (dan juga pendidikan) adalah pada tahap eksplorasi, yang dimulai pada usia sekitar 14 tahun. Pada usia ini individu mengalami tekanan untuk memutuskan mengenai pendidikan dan karir (Slavin, 2006).

Mau\&Bikos (2000) bahwa aspirasi karir pada siswa sekolah menengah atas diyakini para peneliti merupakan prediktor yang paling signifikan atas muara pendidikan dan pekerjaan siswa. Dalam perspektif SCCT, pilihan karir merupakan hal yang dinamis, hal ini disebabkan pilihan karir secara konstan termodifikasi oleh pengalaman-pengalaman belajar dan hasil performa individu (seperti, pencapaian akademik), yang juga dipengaruhi oleh "bagaimana individu mengenali kapabilitas dan hasil yang diperoleh dari performa dirinya" (Lent, Hacket, dkk dalam Rojewski, 2005). Pada fase ini siswa memerlukan informasi yang benar mengenai berbagai macam karir kedepan karena dapat membntuk aspirasi karir.

\section{TEORI DASAR}

Brown (2002), menyatakan bahwa Roe developed a row (fields of nterest) by level (occupational level) classification of occupations. Roe mendata berbagai jenis pekerjaan dan kemampuan yang dibutuhkan untuk menjalankan pekerjaan-pekerjaan tersebut.

Anne Roe (1956) mendeskripsikan sistem klasifikasi pekerjaan secara detail (dalam Sharf, 1992) delapan jenis kelompok pekerjaan tersebut adalah :

1. Pelayanan (service)

Pekerjaan ini terkait dengan pelayanan yang dilakukan oleh seseorang terhadap orang lain. Pekerjaan-pekerjaan yang termasuk didalamnya adalah : psikolog klinis, pekerja sosial, konselor karir, perawat, pelayan dan pembantu.

\section{Kontak bisnis (business contact)}

Orang-orang dalam kelompok pekerjaan ini adalah mereka yang bekerja untuk dapat meyakinkan orang lain, mampu menjual produk. Pekerjaan-pekerjaan yang termasuk didalamnya adalah Humas, sales mobil, sales asuransi, dan sales-sales konvensional.

3. Organisasi

Pekerjaan utama orang-orang dalam kelompok ini adalah manajemen. Termasuk didalamnya adalah orangorang pemerintahan, atau juga mereka yang melakukan manajemen didalam perusahaan-perusahaan, seperti gubernur, akuntan dan sekretaris.

4. Teknologi

Pada kategori ini yang termasuk didalamnya adalah proses pembuatan, produksi, perawatan dan pengantaran barang. Jenis pekerjaannya antara lain insinyur, manajer produksi, pilot, montir listrik, dan operator alat berat.

\section{Lapangan (outdoor)}

Perlindungan terhadap lingkungan, mengembangkan produksi dari kekayaan alam baik pertanian atau perhutanan. Termasuk juga pekerjaan yang terkait dengan sumber daya perminyakan dan batu bara yang ditemukan di danau, sungai atau daerah aliran lainnya. Jenis pekerjaan yang termasuk di dalamnya adalah manajer pertanian, arsitektur alam, pengawas perikanan, buruh tambang dan penebang pohon.

6. Sains

Pekerjaan pada bidang ini terkait dengan pengembangan dan penggunaan 
sains dalam berbagai area kehidupan, seperti : sains alam, sains fisika, sains sosial dan lain sebagainya. Pekerjaan saintifik termasuk didalamnya adalah profesor pada sebuah universitas, ahli farmasi, teknisi medis dan laboratorat.

7. Budaya umum (general culture)

Individu pada kelompok ini cenderung memiliki ketertarikan pada aktivitas kemanusiaan dan budaya. Termasuk di dalamnya adalah komunikasi dan pelestarian budaya. Lingkup pekerjaannya terkait dengan hukum, kementerian, sejarah dan pendidikan. Kepala sekolah dan juga guru bisa berada dalam kelompok ini, tetapi dosen sains akan lebih tepat berada di kelompok 6, profesor seni di kelompok 8. Contohcontoh pekerjaannya antara lain pengacara, editor, guru sekolah dasar, dan penyiar radio.

8. Seni dan hiburan (arts and entertainment)

Kelompok ini termasuk mereka yang membuat dan menampilkan seni kepada masyarakat luas. Areanya meliputi musik, seni, penulisan dan juga atletik. Contoh pekerjaannya antara lain konduktor musik, kurator museum, pemerhati musik, desainer interior, pesepakbola dan penata panggung pementasan.

Sementara untuk 6 level klasifikasi Roe ditujukan untuk melihat jumlah tanggungjawab pekerjaan dan tuntutan kemampuan atau keterampilan dari sebuah pekerjaan, terdiri dari:

1. Profesional dan manajerial 1

Independent responsibility. Kategori ini termasuk di dalamnya adalah mereka yang memiliki tanggungjawab tertinggi di dalam sebuah kelompok kerja. Tanggungjawab mereka cenderung sangat besar dan beragam. Mereka bisa saja adalah para pembuat kebijakan yang duduk di pemerintahan, pendidikan, kesehatan atau perusahaan-perusahaan privat. Pada kelompok sains dan budaya umum, biasanya mereka memiliki pendidikan doktoral. Atau juga mereka yang memiliki pendidikan-pendidikan tinggi dalam kelompok.

2. Profesional dan manajerial 2

Mirip dengan level 1, namun sedikit berbeda dalam hal kebebasan kerjanya atau memiliki lebih sedikit tanggungjawab dibanding mereka yang berada di level ke 1 . Seringnya pada level ini pekerja memiliki gelar sarjana atau master. Kemungkinan mereka juga dilibatkan dalam pembuatan kebijakan terkait kehidupan mereka dan orang lain.

3. Semiprofesional dan usaha kecil

Tanggungjawab mereka hanya sebatas pada orang-orang yang setara dengan mereka. seperti tanggungjawab seorang sersan polisi untuk anggota polisi lainnya, atau penjual retail untuk para pramuniaga. Pendidikan yang dibutuhkan pada level ini seringkali hanya sebata sekolah menengah atas, tetapi kebanyakan dari mereka hanya lulusan dari sekolah teknik atau tingkat diploma.

4. $\quad$ Skilled

Dibutuhan pelatihan tertentu, walaupun hanya sebatas untuk pekerja magang atau pendidikan kerja (kejuruan).

5. Semiskilled

On the job training dan sekolah khusus mungkin dibutuhkan dalam pekerjaan ini. Sebagai contoh supir truk dan supir taksi mungkin menerima latihan tertentu sebelum menjalankan pekerjaannya.

6. Unskilled

Hanya membutuhkan pelatihan sederhana. Pekerja hanya membutuhkan 
petunjuk kerja yang telah disiapkan. Tidak membutuhkan pendidikan khusus.

Berdasarkan klasifikasi Teori Anne Roe inilah kemudian dikembangkan media layanan dalam bidang karir berbasis permainan. Isi dari media tersebut adalah delapan klasifikasi pekerjaan dan enam level pekerjaan.

\section{METODOLOGI}

Penelitian ini dilakukan selama enam bulan Maret-Agustus 2015. Metode penelitian yang diggunakan pada penelitian ini yaitu penelitian pengembangan (Research and Development).

Model yang digunakan adalah model sugiyono. Menurut Sugiyono (2009), langkah-langkah penelitian R \& D terdiri dari 10 langkah sebagai berikut: (1) Potensi dan masalah, (2) Pengumpulan data, (3) Desain produk, (4) Validasi desain, (5) Revisi desain, (6) Ujicoba produk, (7) Revisi produk, (8) Ujicoba pemakaian, (9) Revisi produk, dan (10) Produksi masal. Skema langkah-langkah tersebut ditunjukkan pada gambar berikut.

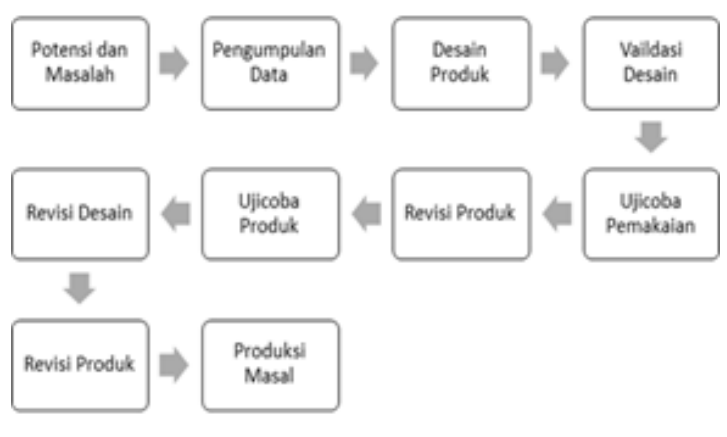

Gambar 1. Skema R\&D

Produk hasil penelitian diuji dengan uji alfa dan beta. Menurut Winarno (2009), produk yang akan diproduksi secara masal harus melewati dua uji tersebut agar peluang kesalahannya kecil. Uji alfa setara dengan review ahli pada model R\&D Sugiyono. Perbedaan uji alfa dengan beta adalah uji alfa merupakan uji produk secara formatif yang dilakukan oleh para ahli sedangkan uji beta adalah uji yang dilakukan oleh para pengguna dalam desain pembelajaran tes ini biasanya bertujuan untuk mengetahui efektifitas media dengan bentuk sumatif tes.

Padapenelitianinitesalfamenggunakan isntrumen yang telah dikembangkan Kustandi dan Bambang (2011). Aspek yang dipertimbangkan adalah media instrumen didasarkan pada indikator prinsip desain dan desain pesan. Pada aspek materi instrumen dikembangkan sendiri yang didasarkan pada teori Winarno (2009), pada pokok bahasan, informasi tambahan, pertimbangan afektif, materi tambahan dan kesesuaian tampilan dengan materi.

Pada tes beta, instrumen dikembangkan sendiri untuk melihat afektifitas media. Efektifitas media dapat lihat dari ketercapaian tujuan pembelajaran yaitu peningkatan wawasan (Winarno, 2009) dan cara mengatahui efektivitas pembelajaran evaluasi dapat didasarkan pada kriteria ketercapaian tujuan layanan (Badrujaman, 2011). Sesuai dengan isi materu pada media dan tujuan pengembangan media maka indikator tes beta yaitu meliputi kesesuian pekerjaan dengan levelnya, kesesuaian pekerjaan dengan bidangnya, kualifikasi umum pekerjaan, lulusan minimal suatu pekerjaan dan kecocokan bidang pekerjaan dengan pendidikannya.

Sampel dipilih secara sampling yang didgunakan adalah quota sampling. Pada layanan dasar, bimbingan kelompok yaitu delapan orang. Sampel uji coba pada tes beta adalah delapan orang. Sampel uji pada penelitian ini yaitu siswa kelas IX SMP Taman Siswa Jakarta, Indonesia, yang berjumlah delapan orang yang terdiri 4 laki-laki dan 4 perempuan. Usia mereka 13 tahun 2 orang, 14 tahun 5 orang, dan 25 tahun 1 orang.

Tujuan penelitian ini adalah untuk mengembangkan produk dan menguji efektivitas media karir "halma roe" yang telah selesai dikembangkan. Pengajuan hipotesisnya yaitu media karir "halma roe" yang dikembangkan efektif digunakan sebagai media pembelajaran. 
Ho diterima apabila Ho: $m_{\mathrm{A}}<m_{B}$

Ho ditolak apabila $\mathrm{H} 1: \boldsymbol{m}_{\mathrm{A}}>\boldsymbol{m}_{B}$

\section{HASIL PENGEMBANGAN}

Pertama penelitian ini dilakukan dengan menelusuri dokumen sekolah. Setelah dilakukan penelitian pada sekolah SMP Taman Siswa tidak memiliki program BK dengan baik dan metode layanan tidak bervariatif (Aidah, 2015). Manurut Aidah juga (2015), reaksi siswa terhadap layanan dasar BK dijuga tidak antusias.

Kedua, setelah mendapatkan temuan tersebut maka direncankan peneltian pengembangan media dalam bidang karir. Ditemukan teori yang cocok yang sesuai dengan media karir yang akan dikembangkan yaitu teori Anne Roe. Ketiga, model teori ditemukan maka dirancang media. Media dirancang menggunakan prinsip permainan papan.

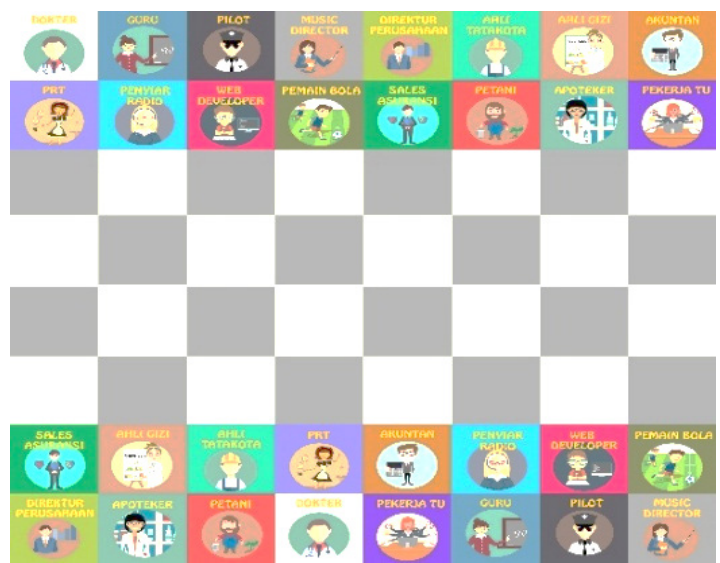

Gambar 2. Desain Awal

Keempat validasi desain, desain yang sudah ada di konslutasikan dengan pakar materi dan media. Pakar materi Dede Rahmat Hidayat, PhD menyatakan desain sudah memenuhi prispip-prinsip belajar dan kesenangan. Perlu diperhatikan bahawa secara tidak sadar permainan ini harus mengajarkan kerjasama dan suportifitas. Disisi lain, pakar media menyebutkan, desain masih kurang menarik, tata letak gambar ilustrasi terbalik pada zone 1.a dan bahan dasar papan yang digunakan masih belum tahan air.

Pada tahap kelima, uji coba pemakaian. Permainan dicoba berkali-kali hingga akhirnya menemukan banyak cara untuk memainkan. Setelah banyak cara tersebut ada satu cara yang dinilai paling menyenangkan dan efektif. Sebagai contoh bidak juga dapat melompati bidak sendiri atau lawan yang berada didepannya dengan jumlah ganjil 1,3,5 dst, keruang kosong dan bidak dapat berhenti sejauh yang pemain mau sesuai dengan setrategi permainan. Jika bidak anda sudah sampai pada terget maka lawan harus teriak "ROE". pemain dapat menghitung hingga lima detik jika lawan lupa maka pemain dapat bilang "BOOM". lalu lawan harus membaca kartu permainan yang dibagi oleh juri, sesuai profesi yang menjadi target.

Pada tahap keenam, desain direvisi dan dihasilkan produk yang dilekngkapi dari aspek materi dan diperbaiki dari aspek desain. Pada proses ini peneliti mulai merancang nama, yaitu media peneliti sebut dengan Halma Roe dan melengkapi zona 2 dengan istilah-istilah dalam sistem kerja di Indonesia. Perbaikan tata letak gambar ilsutrasi yang terbalik pada zona 1a sepert pada zona $1 \mathrm{~b}$, dan penambahan perangakat kartu dan dadu.

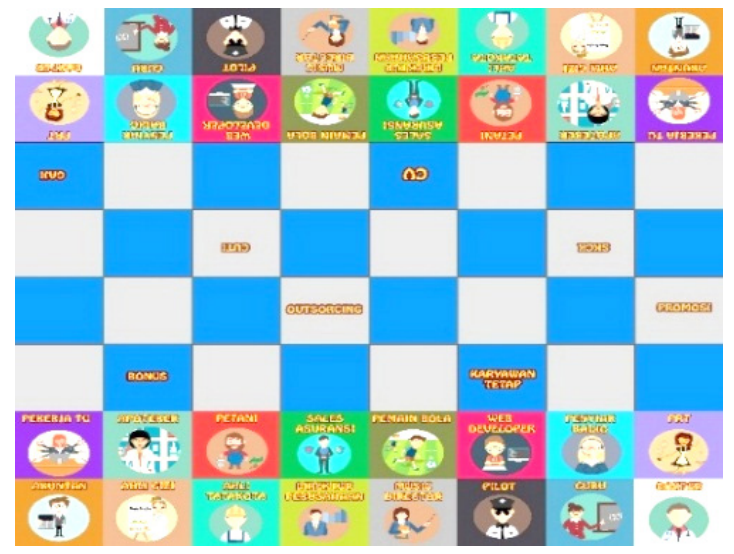

Gambar 3. Revisi Desain 


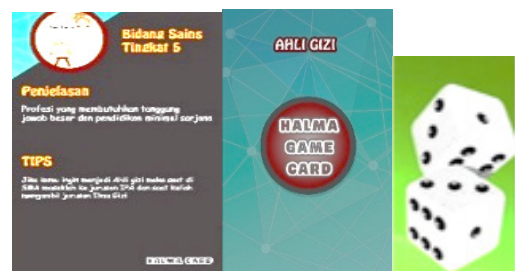

Gambar 4. Beck Card, Front Card, dan Dice

Tahap ketujuh, pada uji ahli media dinyatakan sudah sangat baik dengan skor ratarata 85 yaitu 78 dari ahli materi dan $92 \%$ dari ahli media. Media yang sudah dinyatakan layak untuk digunakan dari aspek ahli selanjutnya dilakukan uji penggunaan (beta tes).

Uji beta media dengan menggunakan desain one group pre and post test only (Arikunto, 2012). Hasil yang diperoleh pretes $=\mathrm{X} 1$, dan hasil yang diperoleh post tes $=$ $\mathrm{X} 2$.

Tabel 1. Perolah Nilai Pre dan Pos

\begin{tabular}{ccc}
\hline NO & X1 & X2 \\
\hline 1 & 84,62 & 96,15 \\
2 & 69,23 & 88,46 \\
3 & 73,08 & 92,31 \\
4 & 84,62 & 96,15 \\
5 & 80,77 & 96,15 \\
6 & 84,62 & 92,31 \\
7 & 57,69 & 88,46 \\
8 & 61,54 & 92,31 \\
\hline Analisi & selanjutnya & dengan
\end{tabular}

menggunakan uji Wilcoxon (Furqon, 2013).

Perhitungan dengan menggunakan SPSS 20.0

Test Statistics ${ }^{\mathrm{a}}$

\begin{tabular}{lr}
\hline & postes - pretes \\
\hline$Z$ & $2,530^{\mathrm{b}}$ \\
Asymp. Sig. (2-tailed) &, 011 \\
\hline
\end{tabular}

a. Wilcoxon Signed Ranks Test

b. Based on negative ranks.

Berdasarkan perhitungan Wilcoxcon Signed Rank Test., maka nilai $\mathrm{Z}$ yang didapat sebesar 2,731 dengan $\mathrm{p}$ value (Asymp.Sig. (2-tailed) sebesar 0,011. Nilai Sig lebih kecil dari batas kritis 0,05 sehingga hipotesis nol Ho ditolak dan $\mathrm{H} 1$ diterima. Hal ini berarti terdapat perbedaan bermakna antara kelompok pretes dan postes.

Berdasarkan kondisi diatas maka tahap ke delapan dan kesembilan tidak perlu dilakukan karena produk sudah dinyatakan sangat baik oleh ahli dan efektif.

\section{KESIMPULAN}

Setelah dilakukan pengembangan dan pengujian, pada penelitian ini berhasil dikembangkan produk media pembelajaran karir. Media ini disebut "Halma Roe". Uji Alfa dengan kategori sangat baik 92\% dan terjadi perbedaan bermakna antara sebelum penggunaan media dan sesudah penggunaan media.

\section{Deskripsi Temuan}

Halma Roe media permainan edukasi untuk wawasan karir. Dasar teori yang digunakan adalah teori karir Anne Roe. Permaianan ini berisi seputar klasifikasi karir meliputi delapan bidang pekerjaan, enam tingkatan dan kualifikasi umum yang dibutuhkan pada enam belas macam profesi.

Roe terdiri dari satu buah papan, kartu dan dadu. Papan permainan yang disebut bidang halma roe. Bidang Halma terdiri dari dua bidang, Bidang A berisi tingkatan pekerjaan 1-3 dan bidang $\mathrm{B}$ berisi pekerjaan dengan tingkatan 4-6. Kartu disebut kartu roe. Kartu Roe berisi deskripsi bidang, tingkatan dan kualifikasi serta tips profesi yang ada pada papan. Dadu disebut dadu Roe merupakan dadu pada umumnya yang berfungsi untu menentukan pemain pertama yang akan berjalan.

\section{Saran}

Pengembangan media layanan konseling di Indonesia masih sangat jarang. Pengembangan ini perlu terus dilakukan dalam rangka peningkatan kualitas pendidikan terutama layanan dibidang bimibingan dan 
konseling. Indonesia memiliki peringkat buruk mengenai pendidikan. Disisi lain konselor masih mencari bentuk, karena ilmu konseling di Indonesia termasuk muda. Berfokus pada masalah diatas, Sesuai dengan tujuan penelitian kali ini maka peneliti berharap ada pengembangan pada bidang media Halma dengan berbagai variasi permainan.

\section{DAFTAR PUSTAKA}

Arikunto, S. (2006). Prosedur Penelitian. Jakarta: Rineka Cipta.

Asosiasi Bimbingan dan konseling Indonesia. (2006). Penataan Pendidikan Profesional Konselor Dan Layanan Bimbingan Dan Konseling Dalam Jalur Pendidikan Formal. Bandung: ABKIN.

Badrujaman, A. (2011). Teori dan Aplikasi Evaluasi Bimbingan dan Konseling. Jakarta: Indeks.

Brown, D. (1996). Career Choice and Development (4th ed.). San Fransisco: Wiley Company.

Departemen Pendidikan Nasional. (2008). Ramburambu Penyelenggaraan BK dalam Jalur Pendidikan Formal. Jakarta: Author.

Erastia, R. (2013). Evaluasi Program Pada Bidang Bimbingan dan Konseling di SMKN 57 Jakarta Selatan. (Unpublished undergraduated thesis) Universitas Negeri Jakarta, Jakarta.

Furqon. (2013). Statistika Terapan untuk penelitian. Bandung: Alfabeta

Harsantik, S. (2014). Pengembangan Media Game Tebak Gambar Untuk Membantu Eksplorasi Karir Siswa Kelas VII SMP Negeri 1 Panggul. Jurnal Unnesa, 4 (3), 1-9.

Kustandi, C. \& Bambang. (2013). Media Pembelajaran Manual Digital (2nd ed.). Jakarta: Ghalia Indonesia.

Mau, Wei-Cheng \& Bikos, L.H. (2000). Educational and Vocational Aspirations of Minority and Female Students: A Longitudinal Study. Journal of Counseling \& Development, 1 (78), 186-194.
Melvin, Silberman. (2006). Active Learning

- 101Cara Belajar Siswa Aktif. Bandung: PT. Nusamedia dan Nuansa.

Rastiwi, Enggar Citra. (2014). Pengembangan Media Ular Tangga Perencanaan Karier Dalam Bimbingan Kelompok Pada Siswa Kelas XI IPS di SMA Negeri 17 Surabaya. Jurnal Unesa, 4(3), p.1-8.

Rojewski, J.W. (2005). Occupational Aspiration: Constructs, Meanings, and Application. In S.D. Brown \&R.W. Lent (Eds), Career Development and Counseling, Putting Theory and Research to Work. New Jersey: John Willey and Sons.

Sharf, R.S. (1992). Applying Career Development Theory to Counseling. New York : Brooks Cole Publishing Company.

Slavin, R. (2006). Educational Psychology: Theory into Practice (10th ed.). Boston: Allyn \& Bacon.

Sugiyono, (2009). Metode Penelitian Pendidikan Pendekatan Kuantitatif, Kualitatif dan $R \& D$. Bandung: Alfabeta.

Suharsimi Arikunto. (2012). Dasar-Dasar Evaluasi Pendidikan. Jakarta: Bumi Aksara.

Winarno. (2009). Teknik Evaluasi Multimedia Pembelajaran. Malang: Genius Prima Media. 